\title{
QUALIDADE DE SEMENTES DE COUVE BRÓCOLIS BENEFICIADAS EM MESA DENSIMÉTRICA ${ }^{1}$
}

\author{
GIZELE INGRID GADOTTI², CARLALIMACORRÊA ${ }^{3}$, ORLANDOANTÔNIO LUCCAFILHO ${ }^{4}$, FRANCISCOAMARAL VILLELA ${ }^{4}$
}

\begin{abstract}
RESUMO - Os resultados de pesquisas desenvolvidas demonstram a eficiência da mesa densimétrica no aprimoramento da qualidade de sementes de diversas espécies, evidenciando superioridade da qualidade fisiológica e sanitária das sementes coletadas nas posições superiores em relação às posições inferiores da zona de descarga da mesa. Considerando o reduzido número de trabalhos publicados sobre beneficiamento de sementes de hortaliças em especial sobre couve brócolis, cujas sementes apresentam diferenças no peso específico em virtude da desuniformidade de maturação das sementes, é importante estudar a influência da utilização da mesa densimétrica na classificação de sementes dessa espécie. O presente trabalho foi realizado com o objetivo de avaliar a qualidade fisiológica e sanitária de sementes de couve brócolis, beneficiadas em mesa densimétrica. As sementes inicialmente foram limpas em máquina de ar e peneiras e a seguir beneficiadas em mesa densimétrica. O eixo terminal de descarga da mesa densimétrica de 1,00m de largura foi dividido em quatro partes. Os tratamentos constituíram das frações obtidas no depósito da alimentação e nas partes: alta, intermediária alta, intermediária baixa e baixa, da zona de descarga da mesa densimétrica. As sementes de couve brócolis descarregadas na parte alta da zona de descarga da mesa densimétrica apresentaram qualidade fisiológica significativamente superior às sementes descarregadas nas partes baixa e repasse da fração intermediária baixa, sendo recomendável a remoção da fração direcionada para a parte baixa, visando o aprimoramento dos atributos fisiológicos e sanitários do lote.
\end{abstract}

Termos para indexação: Brassica oleraceae var. itálica, vigor, beneficiamento, sanidade.

\section{PHYSIOLOGICALAND SANITARYQUALITY OF BORECOLE BROCCOLIS SEEDS BENEFITED ONADENSIMETRICTABLE}

\begin{abstract}
The results of developed research demonstrate the efficiency of the densimetric table in the improvement of the quality of seed lots of diverse species, evidencing superior physiological and sanitary quality of the seeds in the upper positions in relation to the lower positions of the discharge zone. Considering the few reports on the improvement of vegetable seeds, especially borecole broccolis and, moreover the desuniformity of maturation of this species, that is reflected in the specific weight of the seeds, is important to study the influence of the use of the densimetric table on the performance of borecole broccolis seeds. The present study was carried out to verify the physiological and sanitary quality of borecole broccolis seeds, benefited by the densimetric table. The seeds had initially been cleaned in an air machine and sieved and then benefited on the densimetric table. The terminal axle of discharge of the $1.00 \mathrm{~m}$ wide densimetric table was divided into four parts. The treatments consisted of the fractions obtained in the feed deposit and the high, intermediate high, intermediate decrease and low parts of the discharge zone of the densimetric table. The borecole broccolis seeds unloaded in the high part of the discharge
\end{abstract}

\footnotetext{
${ }^{1}$ Submetido em 26/04/2005. Aceito para publicação em 25/10/2005;

${ }^{2}$ Mestranda em Ciência e Tecnologia de Sementes, Universidade Federal de Pelotas; gigadotti@hotmail.com;
}

\footnotetext{
${ }^{3}$ Doutoranda em Fitotecnia da Universidade Federal de Lavras;

${ }^{4}$ Professor, Dr., Departamento de Fitotecnia, FAEM, Universidade Federal de Pelotas. Campus Universitário, Pelotas - RS. Caixa Postal 354, CEP: 96010-900.
} 
zone of the densimetric table presented significantly superior physiological quality to the seeds unloaded in the lower part, and the intermediate fraction decrease, and the removal of the fraction directed for the part low is recommended to improve the physiological and sanitary attributes of the lot.

Index terms: Brassica oleraceae var. itálica, vigor, process, sanity.

\section{INTRODUÇÃO}

A produção e a comercialização de sementes de hortaliças constituem nova tendência de mercado nacional. Conforme a Associação Brasileira do Comércio de Sementes e Mudas (2003), a demanda por sementes de hortaliças para o mercado brasileiro em 2003 atingiu cerca de 175 mil toneladas, movimentando R\$ 226 milhões de reais.

As sementes infectadas por patógenos podem diferir em peso específico das sementes sadias, podendo ser retiradas dos lotes através do beneficiamento de sementes, utilizandose a mesa densimétrica; máquina de acabamento, cujo princípio de separação fundamenta-se em separar materiais que diferem quanto ao peso específico (Bicca et al., 1998). As sementes de menor peso específico, freqüentemente de menor qualidade, são descarregadas na parte baixa da zona de descarga da mesa densimétrica, ocorrência verificada por Buitrago et al. (1991) e Fantinatti et al. (2002) em sementes de feijão, Baudet e Misra (1991) em sementes de milho, Bicca et al. (1998) em sementes de arroz, Alexandre e Silva (2001) em sementes de ervilhaca-comum, Ahrens e Krzyzanowski (1998) em sementes de tremoço, Infantini et al. (1992) em sementes de cornichão, Nascimento (1994) em sementes de ervilha e Giomo et al. (2004) em sementes de café.

Utilizando a mesa densimétrica no beneficiamento de sementes de feijão, Lollatto e Silva (1984) e Buitrago et al. (1991) constataram maior incidência de fungos nas sementes descarregadas na bica correspondente à parte baixa da mesa. Ahrens e Krzyzanowski (1998), em sementes de tremoço e Alexandre e Silva (2001), trabalhando com sementes de ervilhaca-comum, verificaram tendência da concentração das sementes contaminadas com fungos nas partes baixa de descargas inferiores, porém com incidência dependente do patógeno envolvido.

Os resultados de pesquisas desenvolvidas demonstram a eficiência da mesa densimétrica no aprimoramento da qualidade de lotes de sementes de diversas espécies, evidenciando superioridade de qualidade fisiológica e sanitária das sementes coletadas nas posições superiores em relação às posições inferiores da zona de descarga. Dessa forma levando em conta a escassez de informações sobre o beneficiamento de sementes de hortaliças, especialmente couve brócolis e, além disso, a desuniformidade de maturação dessa espécie, com reflexos diretos sobre o peso específico das sementes, é importante estudar a influência da utilização da mesa densimétrica no desempenho de sementes de couve brócolis.

O presente trabalho foi realizado com o objetivo de verificar a qualidade fisiológica e sanitária de sementes de couve brócolis, beneficiadas em mesa densimétrica.

\section{MATERIAL E MÉTODOS}

Foram utilizadas sementes de couve brócolis, procedentes da Sementes Agroecológicas Bionatur, no município de Candiota - RS. As sementes inicialmente foram limpas em máquina de ar e peneiras e, a seguir, beneficiadas em mesa densimétrica, marca Caliver, formato retangular, com capacidade nominal de $1250 \mathrm{~kg}$ por hora.

O eixo terminal de descarga da mesa densimétrica de $1,00 \mathrm{~m}$ de largura foi dividido em quatro partes: baixa com $10 \mathrm{~cm}$, intermediária baixa com $25 \mathrm{~cm}$, intermediária alta com $25 \mathrm{~cm}$ e alta com $40 \mathrm{~cm}$. Os tratamentos constituíram das frações obtidas no depósito da alimentação e nas partes: alta, intermediária alta, intermediária baixa e baixa, da zona de descarga da mesa densimétrica. Esse equipamento foi regulado com quatro quintos da abertura máxima da ventilação, inclinações longitudinal igual à metade da máxima inclinação e lateral três quartos da máxima inclinação.

A amostragem foi procedida retirando-se quatro amostras de cada tratamento, com peso médio de $200 \mathrm{~g}$, em intervalos regulares de tempo de 15 minutos. As amostras coletadas foram acondicionados em sacos de papel e mantidas em câmara fria e seca (temperatura média de $15^{\circ} \mathrm{C}$ e UR de $35 \%$ ) até a realização das seguintes avaliações:

Análise de germinação - conduzida com 200 sementes (quatro subamostras de 50 sementes), distribuídas em rolos de papel toalha, tipo germitest, umedecidos com quantidade de água equivalente a 2,5 vezes o peso do substrato seco e, colocadas em germinador à temperatura de $25^{\circ} \mathrm{C}$. As avaliações 
foram realizadas no quinto e décimo quarto dia após a semeadura, conforme as Regras para Análise de Sementes RAS (Brasil, 1992) e os resultados expressos em percentagem.

Primeira contagem de germinação - executada conjuntamente com o teste de germinação, determinando-se a percentagem de plântulas normais obtidas no quinto dia após a instalação do teste .

Envelhecimento acelerado - conduzido em caixas plásticas, tipo gerbox, com compartimento individual contendo uma bandeja com tela de alumínio onde as sementes $(3 \mathrm{~g})$ foram distribuídas formando uma camada uniforme e $40 \mathrm{~mL}$ de solução não saturada de $\mathrm{NaCl}$ (11g de $\mathrm{NaCl}$ em $100 \mathrm{~mL}$ de água), estabelecendo ambiente com umidade relativa de 94\%, segundo Jianhua e McDonald (1996) adaptado por Ávila (2005). As caixas foram mantidas em câmara B.O.D. a $41^{\circ} \mathrm{C}$ por 48 horas. Decorrido o período de envelhecimento, as sementes foram submetidas ao teste de germinação, seguindo metodologia descrita anteriormente (Brasil, 1992). Paralelamente, foi determinado o teor de água das sementes após o período de envelhecimento.

Emergência das plântulas - foram semeadas duzentas sementes (quatro amostras de 50 sementes) em bandejas de isopor de 200 células, usando substrato para sementes de hortaliças, marca comercial Plantimax, conduzidas em condições de laboratório em temperatura ambiente. $\mathrm{O}$ substrato foi umedecido com água e a semeadura realizada com duas sementes em cada célula. As contagens foram realizadas conforme a RAS (Brasil, 1992), exceto pelo número de sementes.

Índice de velocidade de emergência (IVE) - foi realizada diariamente a contagem do número de plântulas emergidas e o IVE calculado seguindo Maguire (1962) descrito por Nakagawa (1999).

Teste de sanidade - realizado pelo teste de papel filtro foi conduzido com 400 sementes dispostas em recipientes gerbox, previamente desinfestados com solução de hipoclorito de sódio, sobre duas folhas de papel mata borrão umedecidas com água destilada e esterilizada. As sementes foram mantidas em câmara de incubação, à temperatura de $23 \pm 2{ }^{\circ} \mathrm{C}$, em regime alternado de 12 horas de luz e 12 horas de escuro, por período de sete dias, conforme as RAS (Brasil, 1992). Para identificação da microflora, as sementes foram examinadas individualmente com auxílio de microscópio estereoscópio e, quando necessário, microscópio ótico. Os resultados de incidência foram expressos em percentagens de fungos presentes nas sementes.

Procedimento estatístico - o delineamento experimental utilizado foi inteiramente casualizado com cinco tratamentos e quatro repetições. Os dados expressos em percentagem foram transformados em arc-seno da raiz de x/100. Após a análise da variância, as médias dos tratamentos foram comparadas pelo teste de Tukey, ao nível de probabilidade de $5 \%$.

\section{RESULTADOS E DISCUSSÃO}

Na Tabela 1 são apresentados os resultados dos testes para avaliação da qualidade fisiológica das sementes de couve brócolis, que mostram, de maneira geral, maior qualidade nas sementes oriundas das partes altas da descarga da mesa densimétrica em relação à das partes mais baixas, tanto na germinação como no vigor, concordando Buitrago et al. (1991) e Fantinatti et al. (2002) em sementes de feijão, Baudet e Misra (1991) em sementes de milho, Bicca et al. (1998) em sementes de arroz, Alexandre e Silva (2001) em sementes de ervilhaca-comum, Ahrens e Krzyzanowski (1998) em sementes de tremoço, Infantini et al. (1992) em sementes de cornichão, Nascimento (1994) em sementes de ervilha e Giomo et al.

TABELA 1. Dados médios de germinação - G (\%); primeira contagem da germinação - PCG (\%); envelhecimento acelerado (germinação e umidade) - EA(\%); emergência de plântulas - EP(\%) e índice de velocidade de emergência - IVE de sementes de couve brócolis coletadas na alimentação e em quatro posições do eixo terminal de descarga da mesa densimétrica.

\begin{tabular}{|c|c|c|c|c|c|c|}
\hline \multirow{2}{*}{ Tratamento - Fração } & \multirow[b]{2}{*}{ G } & \multirow[b]{2}{*}{ PCG } & \multicolumn{2}{|c|}{ EA } & \multirow[b]{2}{*}{ EP } & \multirow{2}{*}{ IVE } \\
\hline & & & $U$ & $\%$ & & \\
\hline Alimentação & $88 a b$ & $82 a$ & $15,7 a$ & $85 b$ & $84 a b$ & $44,25 d$ \\
\hline Alta & $92 a$ & $86 a$ & $16,7 \mathrm{a}$ & $94 a$ & $90 \mathrm{a}$ & $60,72 \mathrm{a}$ \\
\hline Intermediária Alta & $90 a$ & $82 a$ & $15,8 \mathrm{a}$ & $92 a$ & $86 a b$ & $54,77 \mathrm{~b}$ \\
\hline Intermediária Baixa & $85 \mathrm{~b}$ & $79 a$ & $15,2 \mathrm{a}$ & $85 b$ & $82 \mathrm{~b}$ & $51,38 \mathrm{c}$ \\
\hline Baixa & $65 c$ & $58 \mathrm{~b}$ & $15,7 \mathrm{a}$ & $60 \mathrm{c}$ & $58 \mathrm{c}$ & $28,66 \mathrm{e}$ \\
\hline
\end{tabular}

Médias seguidas pela mesma letra na coluna não diferem entre si ao nível de significância de 5\% pelo teste de Tukey. 
(2004) em sementes de café. Os resultados mostram decréscimo na germinação no sentido da parte alta para parte baixa, sementes descarregadas na parte baixa da mesa densimétrica estão fora dos padrões mínimos de comercialização exigidos pela CESM-RS (1997), sendo para couve brócoli igual a 70\%. O teste de primeira contagem da germinação destacou a inferioridade da qualidade das sementes descarregadas na parte baixa da mesa densimétrica relativamente às demais frações.

Os resultados do teste de envelhecimento acelerado permitiram observar que nos tratamentos há decréscimo do vigor das sementes das partes altas para as partes baixas, concordando com Alexandre e Silva (2001) em sementes de ervilhaca-comum, Lollato e Silva (1984), Buitrago et al. (1991) e Fantinatti et al. (2002) em sementes de feijão, Infantini et al. (1992) em sementes de cornichão e Ahrens e Krzyzanowski (1998) em sementes de tremoço. O teste de emergência de plântulas mostrou-se similar ao constatado nos testes de germinação e envelhecimento acelerado, com as sementes descarregadas na parte intermediária baixa da zona de descarga da mesa apresentando atributos similares aos da alimentação, evidenciando a necessidade de repasse, verificada por Buitrago et al. (1991) em sementes de feijão e por Baudet e Misra (1991) em sementes de milho.

$\mathrm{O}$ índice de velocidade de emergência possibilitou a separação das sementes descarregadas nas quatro partes da zona de descarga da mesa densimétrica em quatro níveis de vigor com superioridade para as sementes da parte alta e inferioridade para as sementes da parte baixa.

No teste de sanidade foi possível detectar a presença de nove espécies fúngicas, as quais podem ser agrupadas em fungos de armazenamento (Aspergillus sp. e Penicillium sp.), patógenos fracos ou potencialmente patogênicos (Fusarium sp., Cephalosporium sp. e Alternaria sp.) e oportunistas (Bipolaris sp., Epicoccum sp., Cladosporium sp. e Trichoderma sp.), porém, apenas Alternaria sp. e Penicillium sp. foram encontrados em proporções que permitiram uma análise estatística dos dados, considerando que os demais fungos ocorreram esporadicamente.

O resultado obtido indica que a mesa densimétrica contribui para a melhoria da qualidade sanitária das sementes, visto que as sementes com maior incidência de fungos, tendem a direcionar-se para as descargas inferiores da mesa.

A melhoria da qualidade sanitária das sementes, com a utilização da mesa densimétrica, também foi observada por Bica et al. (1998) em sementes de arroz, por Alexandre e Silva (2001) em de sementes de ervilhaca-comum e por Ahrens e Krzyzanowski (1998) em sementes de tremoço.

De acordo com a Tabela 2, pode-se observar que as sementes descarregadas na parte alta da mesa apresentaram incidência de Alternaria sp. e Penicillium sp., significativamente inferior às sementes descarregadas na parte baixa da zona de descarga. Isso demonstra que a mesa densimétrica pode promover melhoria na qualidade sanitária das sementes, considerando que um alto percentual de sementes infectadas por patógenos são separadas do lote original e eliminadas na parte inferior do eixo terminal de descarga. Isto ocorre devido à diferença de densidade entre sementes sadias, mais pesadas e as sementes infectadas, mais leves.

Trabalhos realizados por Lollato e Silva (1984) e Buitrago et al. (1991), com sementes de feijão, mostram que a incidência de fungos como Alternaria spp., Fusarium spp. e Macrophomina sp. foi superior nas sementes descarregadas na zona mais baixa da mesa densimétrica.

Os fungos podem causar diversos tipos de danos às sementes, com reflexos significativos na redução da viabilidade. Esses danos geralmente são decorrentes da má formação das sementes, originando sementes chochas, enrugadas, de menor tamanho e peso.Vale destacar que diferenças permitem que sementes atacadas por fungos possam ser eliminadas do lote, possibilitando não apenas a melhoria da qualidade sanitária, como também da qualidade fisiológica do lote de sementes.

Uma análise geral dos resultados obtidos permite afirmar que a mesa densimétrica é eficiente no aprimoramento da qualidade fisiológica de lotes de sementes de couve brócolis, pela remoção das sementes de qualidade inferior na fração descarregada na parte baixa da zona de descarga. Além disso, verifica-se que a mesa densimétrica possibilita redução na

TABELA 2. Incidência de fungos (\%) em sementes de couve brócolis coletadas na alimentação e em quatro posições do eixo terminal de descarga da mesa densimétrica.

\begin{tabular}{lcc}
\hline \multirow{2}{*}{ Posição da Mesa } & \multicolumn{2}{c}{ Fungos } \\
\cline { 2 - 3 } & Alternaria sp. & Penicillium sp. \\
\hline Alimentação & $26,12 \mathrm{ab}$ & $10,47 \mathrm{~b}$ \\
Zona Alta & $22,50 \mathrm{bc}$ & $11,13 \mathrm{~b}$ \\
Intermediária Alta & $20,29 \mathrm{c}$ & $10,94 \mathrm{~b}$ \\
Intermediária Baixa & $21,12 \mathrm{c}$ & $12,00 \mathrm{ab}$ \\
Zona Baixa & $27,75 \mathrm{a}$ & $14,27 \mathrm{a}$ \\
\hline
\end{tabular}

Médias seguidas pela mesma letra, na coluna, não diferem entre si ao nível de significância de $5 \%$ pelo teste de Tukey. 
incidência de fungos do lote de sementes de couve brócolis, reduzindo possíveis perdas de plântulas em pré e pós emergência, como também os demais riscos inerentes à transmissão de patógenos pelas sementes..

\section{CONCLUSÕES}

As sementes de couve brócolis descarregadas na parte alta da zona de descarga da mesa densimétrica apresentam qualidade fisiológica significativamente superior às sementes descarregadas na parte baixa. A eliminação das sementes descarregadas da parte baixa da mesa densimétrica contribui para a melhoria da qualidade fisiológica e sanitária do lote de sementes de couve brócolis.

\section{REFERÊNCIAS}

AHRENS, D.C.; KRZYZANOWSKI, F.C. Efeito do beneficiamento de sementes de tremoço azul sobre suas qualidades física, fisiológica e sanitária. Scientia Agricola, Piracicaba, v.55, n.2,1998.

ALEXANDRE, A.D.; SILVA, W.R. Mesa gravitacional e qualidade fisiológica e sanitária de sementes de ervilhaca-comum. Revista Brasileira de Sementes, Brasília, v.23, n.1, p.167-174, 2001.

ASSOCIAÇÃO BRASILEIRA DE COMÉRCIO DE SEMENTES E MUDAS. Pesquisa de mercado de sementes de hortaliças 2003. Disponível em: <http://www.abcsem.com.br>, Acesso em: 04 abr. 2004

AVILA, P.F. Teste de envelhecimento acelerado na avaliação do potencial fisiológico de sementes de rabanete. 2005. $20 \mathrm{f}$. Dissertação (Mestrado em Ciência e Tecnologia de Sementes) Faculdade de Agronomia Eliseu Maciel Universidade Federal de Pelotas, Pelotas, 2005.

BAUDET, L.; MISRA, M. Atributos de qualidade de sementes de milho beneficiadas em mesa de gravidade. Revista Brasileira de Sementes, Brasília, v.13, n.2, p.91-97, 1991.

BRASIL, Ministério da Agricultura e da Reforma Agrária. Regras para análise de sementes. Brasília: SNDA/DNDV/CLAV, 1992. $365 \mathrm{p}$.

BICCA, F.M.; BAUDET, L.; ZIMMER, G.J. Separação de sementes manchadas de lotes de sementes de arroz, utilizando a mesa de gravidade e sua influência na qualidade sanitária. Revista Brasileira de Sementes, Brasília, v.20, n.1, p.106-111, 1998.

BUITRAGO, I.C.; VILLELA, F.A.; TILLMANN, M.A.A.; SILVA, J.B. Perdas e qualidade de sementes de feijão beneficiadas em máquina de ventiladores e peneira e mesa de gravidade. Revista Brasileira de Sementes, Brasília, v.13, n.2, 1991.

COMISSÃO ESTADUAL DE SEMENTES E MUDAS DO RIO GRANDE DO SUL. Normas e padrões de produção de sementes para o Estado do Rio Grande do Sul. Porto Alegre: Berthier, 1997. 140p.

FANTINATTI, J.B.; HONÓRIO, S.L.; RAZERA, L.F. Qualidade de sementes de feijão de diversas densidades obtidas na mesa gravitacional. Revista Brasileira de Sementes, Londrina, v.24, n.1, p.24-32, 2002.

GIOMO, G.S.; RAZERA, L.F.; GALLO, P.B. Beneficiamento e qualidade de sementes de café arábica. Bragantia, Campinas, v.63, n.2, p.291-297, 2004.

INFANTINI, A.S.G.; IRIGON, D.L.; MELLO, V.D.C.; SANTOS, D.S.B.; ZONTA, E.P. Qualidade física e fisiológica de sementes de cornichão beneficiadas na máquina de ar e peneira e na mesa de gravidade. Revista Brasileira de Sementes, Brasília, v.14, n.2, p.131-134, 1992.

JIANHUA, Z.; McDONALD, M.B. The saturated salt accelerated aging test for small seeds crops. Seed Science and Technology, Zurich, v.25, n.1, p.123-131. 1996.

LOLLATO, M.A.; SILVA, W.R. Efeitos da utilização da mesa gravitacional na qualidade de sementes de feijão. Pesquisa Agropecuária Brasileira, Brasília. v.19, n.2, p.1483-1496, 1984.

NAKAGAWA, J. Testes de vigor baseados no desempenho das plântulas. In: KRZYZANOWSKI, F.C.; VIEIRA, R.D.; FRANÇA NETO, J.B. (Ed.) Vigor de sementes: conceitos e testes. Londrina: ABRATES, 1999, p.2.1-2.23.

NASCIMENTO, W.M. Efeito do beneficiamento na qualidade de sementes de ervilha (Pisum sativum L.). Pesquisa Agropecuária Brasileira, Brasília, v.29, n.2, p.309-313,1994.

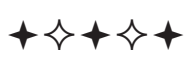

